\title{
Effects of Recognition-based Rewards on Employees' Efficiency and Effectiveness
}

\author{
Shazia Khan \\ Department of Human Resource, Alkaram Towel Industries Pvt. Ltd. \\ Dr. Tayyaba Zarif \\ Newports Institute of Communication and Economics \\ Bilqees Khan \\ Institute of Business \& Technology (IBT) Karachi
}

\begin{abstract}
Purpose-The purpose of this study is to investigate the efficacy of recognitionbased rewards on employees' motivation to be efficient and effective on the job as compared to usual incentives particularly the monetary ones. Study is also aimed to identify role of these rewards on employee retention as well as their long-term effectiveness within organization.

Methodology-For the purpose of study a close ended questionnaire was used to infer the relation between supervisors' recognition (independent variable) and employees' performance, their desire to remain with the organization, and their long term effectiveness in within the organization etc. (dependent variables). Al-Karam Towel Industries (Pvt.) Ltd. Karachi was selected for the study whereat sample size of 100 employees was opted for. The effect of supervisory recognition on employees was examined using $\mathrm{chi}^{2}$ inferential test.

Findings-Findings of the study showed significantly positive relationship between dependent and independent variables.

Practical Implications-This research work is likely to help the organizations realize the worth of recognition as a motivating factor and may persuade them to shift their focus from financial incentives to recognition-based rewards. Findings of the study are also likely to add to the information to the managers that employees of all levels along the hierarchy are influences positively by supervisory recognition for their output and working contribution, and seniority of position is no more bar to it.
\end{abstract}

Keywords : Non-financial benefits, Supervisor recognition, Efficiency, Effectiveness

\section{Jel classification :}

\footnotetext{
* The material presented by the author does not necessarily portray the viewpoint of the editors and the management of the Institute of Business \& Technology (Biztek) or Alkaram Towel Industries Pvt. Ltd and Newports Institute of Communication and Economics.

* Shazia Khan : shaxiakhan@hotmail.com

* Dr. Tayyaba Zarif : dr.tayyabazarif@gmail.com

*Bilqees Khan : khanbilqees3@gmail.com

(C) JMSS is published by the Institute of Business and Technology (Biztek). Main Ibrahim Hydri Road, Korangi Creek, Karachi-75190, Pakistan.
} 


\section{INTRODUCTION \& AIM OF STUDY}

Employees not only want good extrinsic compensation on the work but also want to be praised and valued for the efforts they put in on the work. For many people, incentive and recognition may be overlapping, synonymously used for each other. Whereas, in fact, these two are not the same. Incentives have prospective orientation that make the people work harder to achieve some deadlines and targets preferred by the incentive offering authority, while recognition has retrospective orientation and reflects on an outstanding performance of the employees in the eyes of the recognizer. Distinction between these two types of motivational tools has profound implications over the motivational systems of the organizations though many managers do not understand that may lead to the false people related assumptions. They may fail to recognize that incentives enter the people into a transactional relationship with the organization whereas recognition enters them into transformational vis-à-vis the organization.

Though incentives and recognition both motivate the employees in an organizational perspective, they have different locus of causality - extrinsic and intrinsic respectively. Whereas monetary rewards clearly have external locus of causality, recognition has internal locus of causality. Rather there is a school of thought that argues that application of monetary incentives can actually serve to destroy the intrinsic motivation that may otherwise exist in a work setting. Given this, it is not astounding that many organizations now use non-financial plans to recognize desired employee behaviours.

Organizations that have the motivational systems comprising employee recognition and appreciation at place have found that it leads to higher employee morale and performance levels than even incentives since it, unlike incentives, creates a deep-rooted and long-term ownership among the employees for the organization. Recognizing excellent performance openly builds motivation within the entire organization. It is recognized that employee recognition has contagious effects. When employees see other employees being rewarded for the work they have done it becomes a chain reaction; employees repeat positive actions so that their work will also be appreciated.

Yet, despite the popularity of such plans, very little is known about their actual patterns of use, their relationship, if any, to cash-based reward practices, and factors that may predict their adoption. Accordingly, there is no universal agreement between the employers and the employees over inevitability of the recognition as tool of motivation. Employees may feel undermined if not appreciated for their efforts, while employers may feel that employees are just doing the job they are paid to do. This creates an atmosphere of frustration and high expectations with low performance and motivation. Despite room for such

There is variety of ways of recognizing the people's contribution in the organizations rather than following some standard method for doing it. However, there is an argument that culture of an organization affects the efficacy of a method used for non-financial recognition. It can be embedded into the day-to-day superior-subordinate interactions that make the latter feel that their contribution is appreciated and that they are recognized for their unique qualities they possess. It contributes to high morale in the work environment and increases productivity.

According to Thompson p, Milsome S 2001) non-financial recognition has variety to practice and introduce different range of schemes from range of informal, impromptu and formal structured based. Few examples are here to acknowledge the effort of employees via supervisor:

- Thanks to the employees by Supervisors

- Supervisor's writing formally to record their thanks to recognize employee(s)

- An appreciation in public meeting regarding the efforts. 
- Appreciating in organizational newsletter or at special dinner gathering.

- Declaring Employee of the month or year.

- Holidays tour and travelling

- Meal for the individual and its partner and Home appliance or domestic goods.

\subsection{Aim of Study}

Given employees' increasing emphasis on need for workplace recognition and the ever rising challenges in the areas of employee motivation and productivity, it is imperative that we achieve a better grasp of this concept. Accordingly, this study is being undertaken that will investigate the prospects of non-financial recognition measures undertaken by the management on the employees in the organizations. Particular objectives of the study are:

i. To identify and determine the effect of non-financial benefits on employees' motivation.

ii. To identify the impact of non-financial recognition on different levels/grades of employees.

iii. To analyze the effect of different types of non-financial recognition on competition among employees.

iv. To explore the effect of supervisor's recognition as a non-financial rewards tool for employee retention.

v. To identify the effect of long term non-financial recognition on employees' effectiveness.

vi. To determine the effect of non-financial rewards on employee's performance.

Al-Karam Towel Industries (Pvt.) Ltd. was selected for the study. Data was collected randomly from 40 employees of the organization, all employees of AKTI working at the head office, Karachi with at least three years of experience with the organization.

\subsection{Research Hypotheses}

H1: Supervisors' recognition has a significant impact on employees' performance.

H2: Supervisory recognition is free of hierarchical grades and levels.

H3: Increase in performance based non-financial recognition/rewards has positive effects on employees' performance.

H4: Variety of non-financial recognition rewards positively enhances competition among employees.

H5: Supervisory recognition based rewards have positive effects on employees' retention.

H6: Non-financial recognition rewards have impact on employees' long term effectiveness.

\section{LITERATURE REVIEW}

Existing literature on the subject establishes and clarifies the concept of employee recognition in the work place. Numerous renowned researchers like Herzberg, Mausner and Snyderman (1959); McGregor (1960); Vroom (1964); Porter and Lawler (1968) whose seminal work opened the avenues for unending research and theory formation in the field of employee motivation highlighted employee recognition as an essential component of motivation. These authors stipulate that organizational performance is determined by gaining intrinsic and extrinsic rewards. Several other studies support this theory, which can be referred to as recognition based rather than incentive based motivation as a predictor of organizational performance (Deci and Ryan 2000).

Towers (2003) argues in favour of the recognition based reward rather than performance incentives. He refers to research he conducted over high performing companies 
in U.S. and Canada and concluded that (57\%) of them made significantly greater use of recognition plans rather than incentives compared to the low performers $(36 \%)$. Likewise, Serino (2002) highlights efficacy of recognition based rewards referring to a research conducted on a United States bank and saying that, the post-performance recognition programmes generated 6.5 percent higher level sales per employee, compared to 4.0 percent sales per employee under cash-based incentive plan. However, the most credible empirical verification on the efficacy of recognition based programs emanated from Stajkovic and Luthans' (2003) work who found that use of recognition programmes increased employee performance by an average of $17 \%$.

McAdams (1995) says recognition programmes involve rewards of both kinds i.e. monetary as well as non-monetary nature. Modes of recognition may consist of social reinforcers, such as making mention in the company newsletter; plaques or letters of commendation; travel prizes; or extra time off, and even the verbal appreciation privately or publically etc. These findings are in lines with the findings of Brun and Dugas (2008) who contend that, for the beneficiary, recognition represents a reward experienced primarily at the symbolic level, however, it may also envisage emotional, practical or ?nancial value to any extent.

McAdams (1995) joins the chorus of Serino (2002) and Stajkovic and Luthans (2003) and claims that non-cash recognition awards are not only more motivating but are also economical compared to cash incentives. In his research on some 600 firms, McAdams found that cash incentives, no doubt, enhanced sales performance by $13 \%$ but only through additional 12 percent cost. In contrast, non-financial recognition based rewards also enhanced sales performance to the same level but against cost of only 4 percent. Jeffrey and Schaffer (2007) had almost similar conclusions out of their research who found that non-financial recognition based rewards are not only motivationally superior to cash rewards but also, from the employer perspective, they are favoured since the employer does not need to pay out any cash, which is a scarce resource in most organizations. Kohn (1993b) expresses the same point of view saying that employers are turning to recognition programs to spur productivity and acknowledge. Not only is non-cash recognition costeffective, it's a crucial piece of keeping employees engaged.

Saunderson 2004 identifies the essential nature of employee recognition as a vector of motivation, a component of meaningful work, an agent of personal development, and centre for workplace mental health. Research findings of Brun and Biron et al. (2003) show that dearth of sense of recognition among the workforce in the organizations signals risk of psychological distress and, in the result, an antagonism towards the management. Evans (2001) says that managerial recognition of the employee performance is one of the most salient sources of employee engagement and mobilization and plays cardinal role in organizational change and continuity towards success.

De Cenzo, (1996) stated that recognition based rewards can build and bring the good feelings, strong confidence and ultimate satisfaction among the employees of the organization. Rousseau \& Ho (1978) have also concluded the same result as the say that many employees consider recognition-based rewards are more honored than the incentives.

\section{RESEARCH METHODOLOGY}

The study is of cause and effect nature. Target organization was of Al-Karam Towel Industries (Pvt.) Ltd. Karachi. Data was collected randomly from 100 employees who had more than three years of service with the organization. These employees belonged to departments of Export Marketing, Merchandising, Accounts and Finance, Human Resource and Recovery Departments. Response rate to the questionnaire remained almost $90 \%$. To test the hypotheses, Chi-Square $\left(\mathrm{X}^{2}\right)$ tests were performed in MS-Excel on different variables and the decision of acceptance and rejection of hypothesis was concluded on the basis of results obtained. 


\section{STATISTICAL DATA ANALYSIS}

Consolidated Table for Analysis

\begin{tabular}{|c|c|c|c|c|}
\hline Hypothesis\# & $\begin{array}{l}\text { Degree of } \\
\text { Freedom }\end{array}$ & $\begin{array}{l}c^{2} \text { Cal Value on } \\
0.05 \infty \text { and } 0.01 \infty\end{array}$ & $\begin{array}{c}c^{2} \text { Tab Value } \\
\text { on } 0.05 \infty\end{array}$ & $\begin{array}{c}c^{2} \text { Tab Value } \\
\text { on } 0.01 \infty\end{array}$ \\
\hline $\mathrm{H}_{1}$ & 3 & 39 & 7.815 & 11.345 \\
\hline $\mathrm{H}_{2}$ & 6 & 0.333 & 12.592 & 16.812 \\
\hline $\mathrm{H}_{3}$ & 4 & 27.5 & 9.488 & 13.277 \\
\hline $\mathrm{H}_{4}$ & 3 & 12.9 & 7.815 & 11.345 \\
\hline $\mathrm{H}_{5}$ & 3 & 14.9 & 7.815 & 11.345 \\
\hline $\mathrm{H}_{6}$ & 3 & 35 & 7.815 & 11.345 \\
\hline
\end{tabular}

\subsection{Individual Significance}

\section{Hypothesis 1}

The statistical analysis lead to the findings that at D.F $=3$ and level of significance at $5 \%$ and at $1 \%$, the Chi-square calculated value is greater Chi-square tabulated value which shows that supervisors' recognition has a significant impact on employees' motivation. Hence hypothesis $\mathbf{H}_{\mathbf{1}}$ stands accepted that lead to conclusion that effort and performance of the employees dully recognized by the managers positively effects the employee motivation.

\section{Hypothesis 2}

To analyze whether there exists a difference between hierarchical positions and the supervisors' recognition, chi-square was calculated at 5\% level of significance and DF at 6. Since the calculated value of Chi-Square 0.333 is less than the tabulated value 12.592 it was concluded that there is a significant difference between supervisor's recognition and different levels of employees. Furthermore, statistical analysis at D.F $=6$ and Level of significance of 0.01 , the calculated value of Chi-Square 0.333 is less than the tabulated value 16.812, that again shows that the supervisor's recognition and different levels/ grade/status of employees have significant difference. Hence the $\mathrm{H}_{2}$ stood rejected that lead to the conclusion that the supervisor's recognition does effect different levels/ grade/status of employees.

\section{Hypothesis 3}

Here again statistical analysis was conducted at two different levels of significance i.e. $5 \%$ and $1 \%$. At $5 \%$ level of significance and $\mathrm{DF}=4$, the statistical results showed that ChiSquare 27.5 is more than the tabulated value of 9.488 and at $1 \%$ level of significance and $\mathrm{DF}=4$, the statistical results again showing that Chi-Square 27.5 is more than the tabulated value 13.277. In both the cases, it was found that when recognition based rewards are increased it creates positive impact on employees' performance. So, $\mathrm{H}_{3}$ stood accepted that lead to conclusion that increase in performance based recognition positively effects employees' performance.

\section{Hypothesis 4}

Statistical results show that when Chi-square statistical analysis is conducted at $5 \%$ level of significance and at $\mathrm{DF}=3$, the Chi-square values is greater than Chi-square tabulated. Similarly, at level of significance of $1 \%$ or 0.01 , the Chi-square is again more than tabulated that lead to the conclusion that variety of recognition rewards positively enhance competition among employees. Hence, $\mathrm{H}_{4}$ stood accepted that concludes that the variety of recognition 
based rewards positively enhance competition among employees

\section{Hypothesis 5}

Statistical results also showed that supervisory recognition creates positive effects on employees' retention as results at both $5 \%$ and $1 \%$ level of significance and DF $=03$ clearly show that Chi-Square value of 14.9 is more than the tabulated values of 7.815 and 11.345 respectively. Hence $\mathrm{H}_{5}$ also stood accepted that lead to conclusion that the supervisory recognition positively affects the employees' retention in the organizations.

\section{Hypothesis 6}

In case of last hypothesis, statistical analysis has shown that at D.F $=3$ and level of significance of 0.05 , the calculated value of Chi-Square 35.00 is more than the tabulated value of 7.815. Secondly, at level of significance of 0.01 , the calculated value of ChiSquare 35.00 is also more than the tabulated value of 11.345 . It means recognition based rewards positively impact the employees' effectiveness in long term. It leads to acceptance of $\mathrm{H}_{6}$ that lead to conclusion that the recognition based rewards positively impact employees' effectiveness in the longer run.

\section{CONCLUSION}

The study showed generally a positive correlation between the supervisory recognition and employee motivation and performance in the result. The study concluded that such motivation arising out of recognition is not hierarchy-level specific. Rather it shows positive effects all along the hierarchy. It showed that employees regardless of their seniority level need their efforts and achievements dully recognized by their seniors. Majority of respondents also showed a clear linkage between the employee motivation and performance. They were of the view that when people get motivated because recognition awarded by the managers, they become more energetic intrinsically and hence more

$75 \%$ of the employees said that recognition of their efforts and performance level by the supervisors gives them direction to follow or to keep what they already were following. They believed that it is the best kind of feedback that they could get on the job. The data also showed that respondents believed that supervisory recognition also enhances employee retention rate since it involves identification of their outstanding performance that satisfies their esteem needs and confirms them as significant part of the organization.

This study establishes efficacy of supervisory recognition in organizational perspective. In this way it corroborates numerous studies conducted earlier and discussed upon in the literature review. So, we recommend that the organizational mangers should ensure use of formal performance and efforts recognition programs in the organizations. They should also properly train the managers in this regard because study has shown that verbal appreciation by the managers in day-to-day matters on the job is even stronger motivators. It is mainly because formal citations may be delayed which may result in reduced motivation potential. Whereby verbal appreciation and recognition is instant that is more productive.

\section{REFERENCES:}

1. Appelbaum, S.H., and Kamal, R. (2000), An Analysis of the Utilization and Effectiveness of Non-Financial Incentives in Small Business, The Journal of Management Development, 19, 9/10, 733-763.

2. Brun, J-P., and Dugas, N. (2008), An Analysis of Employee Recognition, Perspectives on Human Resources Practices, International Journal of Human Resource Management, 19, 4, 716-730. 
3. De Cenzo, David A. \& Robbins, Stephen P. (1996) Human Resource Management, New York: John Wiley \& Sons, Inc.

4. Deci, E., and Ryan, R. (2000), The 'What' and 'Why' of Goal Pursuits: Human Needs and the Self- determination of Behaviour, Psychological Inquiry, 11, 4, 227-268.

5. Evans, R. (2001), The Human Side of School Change; Reform, Resistance, and the Real-life Problems of Innovation, San Francisco, CA: Jossey-Bass.

6. Herzberg, F., Mausner, B., and Snyderman, B. (1959), The Motivation to Work, New York: Wiley.

7. Jeffrey, S.A., and Schaffer, V. (2007), The Motivational Properties of Tangible Incentives, Compensation and Benefits Review, May-June, 44-50.

8. Kohn, A. (1993b), Punished by Rewards, Boston, MA: Houghton-Mif?in.

9. McAdams, J.L. (1995), 'Rewarding Special Performance: Low-cost, High-impact Awards,' in The Performance Imperative: Strategies for Enhancing Workforce Effectiveness, (eds). H. Risher and C. Fay, San Francisco, CA: Jossey Bass, pp. 361388.

10. McGregor, D. (1960), The Human Side of Enterprise, New York: McGraw-Hill.

11. Porter, L., and Lawler, E. (1968), Managerial Attitudes and Performance, Homewood: Irwin.

12. Rousseau \& Ho, 1978, Understanding human motivation: cognitive approach, Macmillan publishing Co Inc

13. Saunderson, R. (2004), Survey Findings of the Effectiveness of Employee Recognition in the Public Sector, Public Personnel Management, 33, 3, 255-276.

14. Serino, B. (2002), Non-cash Awards Boost Sales Compensation Plans, Workspan, 45, 8, 24-27.

15. Stajkovic, A.D., and Luthans, F. (2003), Behavioral Management and Task Performance in Organizations: Conceptual Background, Meta-analysis, and Test of Alternative Models, Personnel Psychology, 56, 155-194.

16. Towers Perrin (2003), Managing Performance and Rewards in a Challenging Business Environment, New York: Towers Perrin.

17. Vroom, V.H. (1964), Work and Motivation, New York: Wiley. 